University of Nebraska - Lincoln

DigitalCommons@University of Nebraska - Lincoln

1971

\title{
Morphology of the Spores of Myxosoma cerebralis (Hofer, 1903) and M. cartilaginis (Hoffman, putz, and Dunbar, 1965)*
}

Glenn L. Hoffman

US Fish and Wildlife Service

Jiří Lom

University of Illinois at Chicago Circle

Follow this and additional works at: https://digitalcommons.unl.edu/usfwspubs

Part of the Aquaculture and Fisheries Commons

Hoffman, Glenn L. and Lom, Jiří, "Morphology of the Spores of Myxosoma cerebralis (Hofer, 1903) and M. cartilaginis (Hoffman, putz, and Dunbar, 1965)*" (1971). US Fish \& Wildlife Publications. 108.

https://digitalcommons.unl.edu/usfwspubs/108

This Article is brought to you for free and open access by the US Fish \& Wildlife Service at DigitalCommons@University of Nebraska - Lincoln. It has been accepted for inclusion in US Fish \& Wildlife Publications by an authorized administrator of DigitalCommons@University of Nebraska - Lincoln. 


\title{
MORPHOLOGY OF THE SPORES OF MYXOSOMA CEREBRALIS (HOFER, 1903) AND M. CARTILAGINIS (HOFFMAN, PUTZ, AND DUNBAR, 1965)*
}

\author{
Jiri Lom \\ Department of Biological Sciences, University of Illinois at Chicago Circle, \\ Chicago, Illinois $†$ \\ and \\ Glenn L. Hoffman \\ Bureau of Sport Fisheries and Wildlife, Eastern Fish Disease Laboratory, \\ Kearneysville, West Virginia 25430
}

\begin{abstract}
The spore of Myxosoma cerebralis is redescribed and compared with that of a close relative, M. cartilaginis. M. cerebralis is smaller, with greater variability in size and shape. It possesses a mucous envelope whereas $M$. cartilaginis does not. The surface architecture of $M$. cerebralis, as seen with the scanning electron microscope, differs in possessing a conspicuous circumsutural groove, prominent polar filament pores, and a mucous envelope.
\end{abstract}

Since a unanimous decision on the correct generic status of $M$. cerebralis has not been reached, we continue in this paper to call this species Myxosoma cerebralis, in spite of the views of Walliker (1968) and Lom (1969), who do not consider the absence of the iodinophilous vacuole as adequate reason to warrant generic separation of Myxobolus and Myxosoma and consider the latter a junior synonym of the former. Myxosoma cerebralis, one of the most notorious myxosporidean species, is the causative agent of whirling disease of salmonid fish. This parasite, discovered first in Germany, has been subsequently found in other European countries, the United States, far eastern USSR territories, and even South Africa (Hoffman, 1970). According to Shulman (1966) and Hoffman, Dunbar, and Bradford (1969) it has thus far been found in the following species: Oncorhynchus gorbuscha, O. keta, O. kisutch, O. masu, O. tshawytscha, Salmo gairdneri, S. salar, S. trutta, Salvelinus fontinalis, S. leucomaenis, S. malma, S. namaycush, and Thymallus thymallus. Quite recently, whirling disease has been reported to have

Received for publication 27 April 1971.

* Supported in great part by NSF Research Grant GB 7013X to Dr. John O. Corliss, to whom the senior author is indebted for the use of his research facilities.

$\dagger$ Present address: Institute of Parasitology, Czechoslovak Academy of Sciences, Prague, Czechoslovakia. spread through additional areas of the United States (Hnath, 1970; Yasutake, 1970).

While Shulman (1966) supposes that $M$. cerebralis has long had an holarctic distribution, occurring in naturally infected water reservoirs or streams from which it is able to spread and infect cultured salmonids, it is generally assumed that the recent appearance of $M$. cerebralis infections in North America is due to the importation of infected fishes from Europe. The final solution of this problem would require, among other things, a complex comparative analysis of $M$. cerebralis from European, Asian, and American sources, including a detailed morphological evaluation. Such a morphological analysis would rely largely on the morphology of the spores and similar comparisons should also be made for other myxosporidean species. Curiously enough, no accurate description of spores of $M$. cerebralis is offered in the literature.

Kudo (1920), in his now classical monograph, used spore drawings made by Plehn (1904). These rather simple drawings show a certain degree of spore variability, and depict the spores as having a protruding and narrow sutural valve. The more recent and authoritative monograph of Shulman (1966) again uses the drawings of Plehn, in addition to more recent but schematic drawings of the spores. In other publications on $M$. cerebralis, the spores are also represented very schematically. Everyone seems somehow to take the definition of 
M. cerebralis for granted, and yet it may be very desirable, for practical reasons, to know the degree of differences, biological as well as morphological, among the populations of $M$. cerebralis from individual species of salmonid fishes and its difference from populations in other possible hosts. Ramirez Medina (1962), e.g., reported $M$. cerebralis also from Tinca tinca, Gobio gobio, Esox lucius, and Perca fluviatilis; Volf (pers. comm., 1965) found an allegedly different strain (or species?) of $M$. cerebralis in Thymallus thymallus. An exact knowledge of the spore would therefore be very useful for purposes of definitive determination.

A well-founded differentiation of $M$. cerebralis from other cartilage- and bone-invading species of Myxosoma such as M. hoffmani, $M$. dentium, and $M$. cartilaginis would also be useful. In the case of the last species, the authors themselves point out its close resemblance to $M$. cerebralis, claiming that the spore differs mainly in being larger.

The purpose of this communication is to give an accurate redescription of the spore of $M$. cerebralis and to point out how the spore could be used for differential diagnosis, using as an example the cartilage-invading $M$. cartilaginis.

\section{MATERIALS AND METHODS}

Only fresh (not preserved) spores were used for our observations, since fixation causes changes in size and structure of the spores (Kudo, 1921). The spores of $M$. cerebralis were obtained from trout fingerlings (Salmo gairdneri) artificially infected at the Eastern Fish Disease Laboratory. The fish and infections were about 5 months of age. Spores of $M$. cartilaginis were retrieved from moderate infections in bluegills (Lepomis macrochirus) from rearing ponds at the Eastern Fish Disease Laboratory. No special methods were necessary because large masses of spores were obtained almost completely free of other particles.

It is difficult to separate the spores of $M$. cerebralis from fish tissue. Halved fish heads were digested in aqueous pepsin-HCl solution (pepsin $0.5 \%, \mathrm{HCl} 0.5 \%$ ) at $39 \mathrm{C}$ for $2 \mathrm{hr}$. The softened tissue was removed under the dissecting microscope with forceps and the remaining skeletal parts macerated with a mortar and pestle. The macerated material was screened through 224-, 154-, and 70- $\mu$ mesh screens to remove tissue and the spores were allowed to settle out at $6 \mathrm{C}$. These spores were not visibly different from those not so treated.

In addition to the direct observation of the above spores, photomicrographs were made by employing the technique described in an earlier paper (Lom, 1969). To reveal the presence of mucous envelopes we used the simple India ink technique (Lom and Vavra, 1963).

For scanning electron microscopy, the spores of $M$. cerebralis were prepared essentially according to the technique of Marszalek and Small (1969). The fresh spores were further separated from the tissue debris by means of pipettes and micropipettes, and a drop of the suspension with concentrated spores was placed on a microscope slide. The spores settled and adhered slightly to the glass surface, allowing for further washing by adding and withdrawing distilled water by micropipettes. After several such washing procedures, spores were covered by Parducz fixative ( 1 part of saturated $\mathrm{HgCl}_{2}$ to 6 parts of $2 \%$ osmic acid) for about $6 \mathrm{~min}$, after which the spores were thoroughly washed on the slide with distilled water.

Drops of spore suspension of about the size of a pinhead were placed on the supporting specimen stubs, several drops to each specimen stub. Some of the stubs were coated thinly with a toluene extract of the glue from the transparent doublecoated tape (3M Corporation) for better adhesion and to minimize the static charge of the specimen. The spores were then allowed to settle in the drops and were quickly frozen by plunging the stubs into liquid nitrogen. The subsequent sublimation was performed overnight in a tissue lyophilizer. After a thorough gold coating the stubs were examined with a Cambridge Stereoscan Mark III electron microscope operated at 10 and $20 \mathrm{kv}$ accelerated voltage. Our attempts at preparing sections for electron microscopy were unsuccessful.

\section{RESULTS}

(a) Myxosoma cerebralis (Hofer, 1930). In frontal view (perpendicular to the sutural plane) the spores are mostly broadly oval, sometimes more elongated, rarely completely circular, and exceptionally broader than long (Fig. 1). Although it does not show in the photomicrographs, the spores are often asymmetrical. In side view they are broadly lenticular, both shell valves being considerably vaulted, sometimes one more than the other. The dimensions of 40 spores taken from 5-, 8-, and 11-month infections were: length 8.7 (7.4 to 9.7) $\mu$, width 8.2 (7 to 10 ) $\mu$, thickness 6.3 (6.2 to 7.4) $\mu$. The spore wall could not be measured accurately but appeared to be about $0.25 \mu$ thick. When viewed from the polar capsule end, three very faint striations (grooves?) were seen on some specimens in bright light microscopy.

The oviform polar capsules measured 5.1 ( 5 to 6 ) by 3.2 ( 3 to 3.5 ) $\mu$. Rarely, one polar capsule is slightly larger than the other. As a rule, there is no true intercapsular appendix; in 


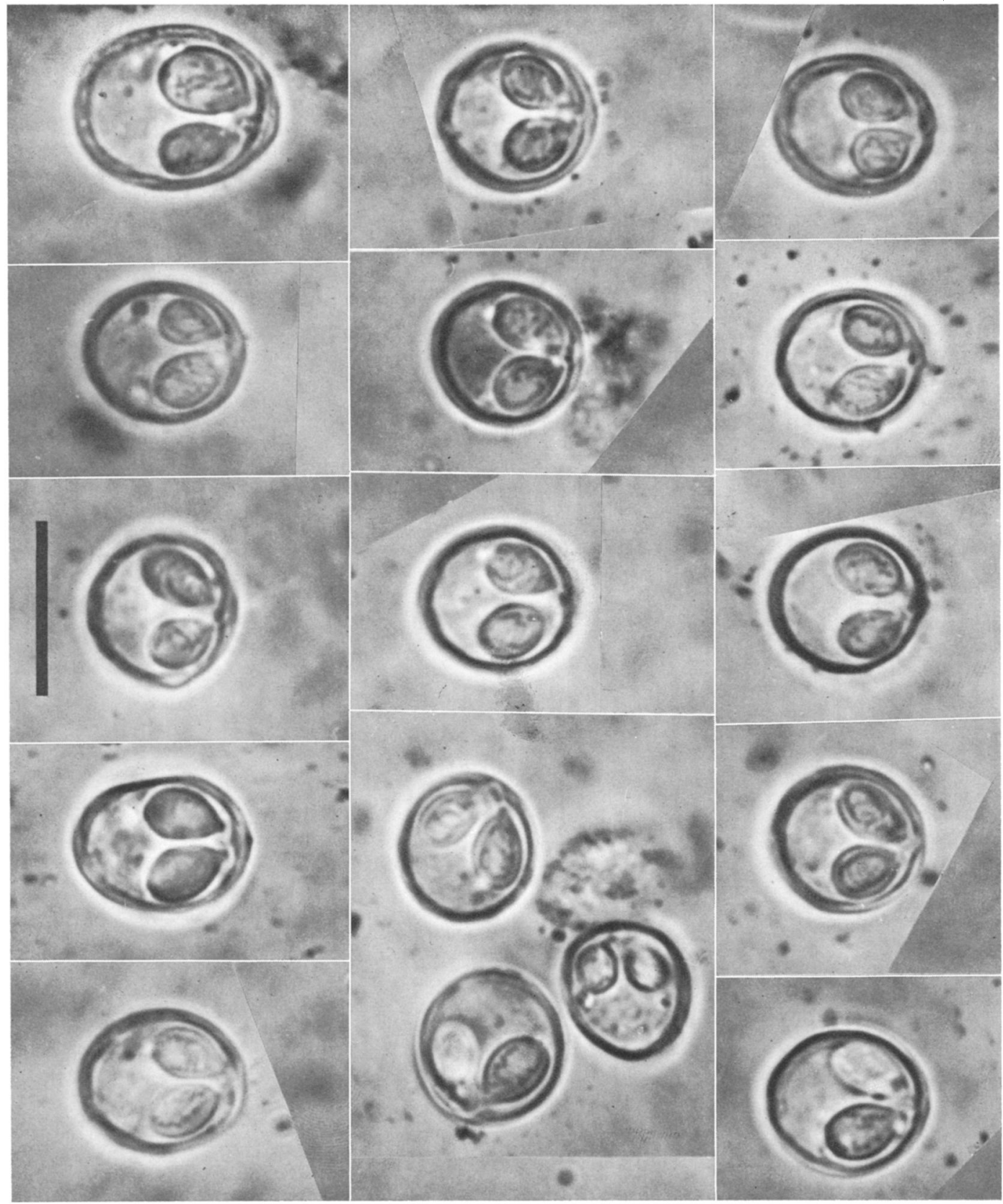

Figure 1. Variation in shape of fresh Myxosoma cerebralis spores from rainbow trout fingerlings. The most typical spores are in the right column-spores are oval, almost circular in outline with equal polar capsules. The left column shows rather aberrant spores, either by shape or by unequal size of polar capsules. $\times 3,000$; the line indicates $10 \mu$.

most cases the border of the shell valves at the anterior end is only slightly thickened on the inner face, forming a ledge separating the discharging canals of the polar capsules. The hypothetical extensions of the longitudinal axis of the capsules always cross anteriorly but the converging pointed anterior ends of the capsules sometimes just overlap in the front view, sometimes lying more or less apart. The filament usually makes five or six coils, rather 
loose and irregular, inside the capsule; it is not very distinct in this species.

In front view, the posterior border of the spore does not exhibit any distinct markings, but the inner outline of the posterior border is generally uneven. India ink reveals a typical mucous envelope around the posterior end of the spore (Figs. 2-4). One of us (J.L.) observed this mucous envelope on $M$. cerebralis sometime ago in France on spores not treated with pepsin digest solution; it is evidently a constant character of fresh spores. After a period of storage in the refrigerator, the mucous coat diminishes a little, but persists for months. The sporoplasm with two nuclei fills the rest of the spore space.

Observed in the scanning electron microscope, the spores of $M$. cerebralis are characterized by the presence of a deep ridge running parallel to the sutural border. Our experience with scanning electron microscope observations of myxosporidean spores is limited, but we did not observe such a deep furrow in spores of several other species. The furrow circumvents the thickened part of the sutural border of the anterior end of the spore. The sutural border of the valve bears at that spot an opening which is presumably the mouth of the discharging canal of the polar filament (Figs. 6, 7). The openings seen in Figure 7 are obviously an anomaly, or one opening split into two; in Myxosoma and Myxobolus, each of the two valves bears the opening for the filament of one of the polar capsules (Lom, 1964). Here again, an open, gaping discharging canal in the shell valve border is different from the spores of other myxosporidean species observed thus far.

The shell valves of the spore are shrunk a little in most of the spores, more posteriorly than anteriorly, where the rigid polar capsules give support to the spore wall. The degree of shrinkage in individual spores varies, but as a rule the majority of all observed spores always reveals some degree of shrinkage.

Posteriorly, the surface of the spore is covered by an irregular network of intertwined strands, which represent constituents of the mucous envelope. Some of the thin mucous strands are also seen to cross the circumsutural furrow (Figs. 6, 7). In some of the spores, the shell valves are clearly asymmetrical (Fig. $5)$. b) Myxosoma cartilaginis (Hoffman, Putz, and Dunbar, 1965). In frontal view (Fig. 8) the spore is oval, of a very regular shape and a quite uniform size-11.25 (10.7 to 11.7 ) by 9.5 (9 to 10) $\mu$. The variation is thus less than in $M$. cerebralis. The present measurements are only slightly larger than those given in the original description by Hoffman et al. (1965). There are six to nine, usually eight, rather indistinct sutural markings at the posterior border of the spore. Anteriorly, there is a triangular thickening of the spore wall border. In side view, the spore is broadly lenticular. The two always equal polar capsules converge less than in $M$. cerebralis, forming a smaller angle, and their pointed anterior ends never overlap in front view. The size of the capsules averages 5.75 by $3.5 \mu$, varying very little. There are usually seven coils of polar filament in the capsule, the threads being tightly but not very neatly arranged.

There is no mucous envelope around the spore, and no iodinophilous vacuole in the binucleate sporoplasm filling the rest of the space within the spore.

In the scanning electron microscope, the spores reveal a smooth surface without any trace of mucous strands, and there is no furrow parallel to the sutural line of the spore (Figs. 9, 10). In most cases, the surface of the spore is rather shrunken into furrows and ridges, and only a small number of spores seems to have resisted shrinkage.

\section{CONCLUSIONS}

We intentionally refrained from presenting drawn pictures of spores, which, though being easier to reproduce than photographs, represent a certain risk of schematization, do not accurately illustrate how the spores look in the microscope, and are less suitable for demonstration of variability. Our material clearly indicates the differences between the two species and we hope the same scrutiny will be done with other Myxosoma species. In the case of $M$. cerebralis, these initial observations, performed on material from typical cases of whirling disease, should be followed by a study of variation and distinctions of various strains from different hosts and areas of distribution. Combined with a computerized, statistical evaluation of quantitative data, it should yield 


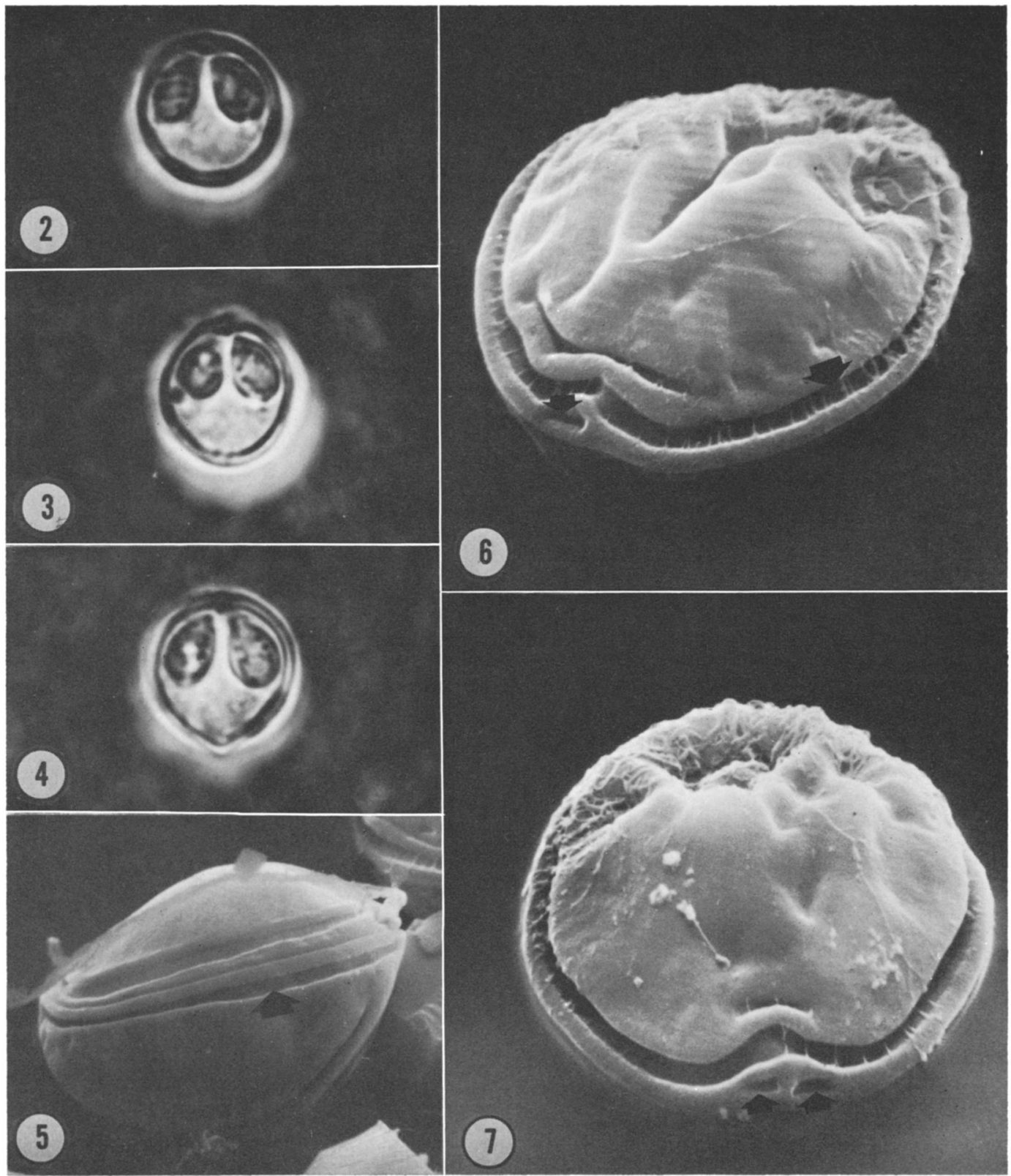

Figures 2-4. Fresh spores of $M$. cerebralis in India ink to show the mucous envelope unpenetrated by the suspended India ink particles. The mucous coat is especially thick on the posterior half of the spore. These spores were recovered from a rapid digestion sample. $\times 3,000$.

Figures 5-7. M. cerebralis spores as seen in the scanning electron microscope. 5. The spore wall reveals almost no shrinkage; one of the shell valves is more vaulted than the other. The furrow along the sutural line is quite distinct. $\times 9,500$. 6. The spore in an upper anterior view. Notice the characteristic furrow parallel to the sutural line, the fine mucous strands concentrated on the posterior half of the spore, and the seemingly open canal for filament discharge in the thick sutural border of the shell valve at the left. $\times 11,000$. 7. Same as in Figure 6; the opening of the canal for filament discharge seems to be split into two. 


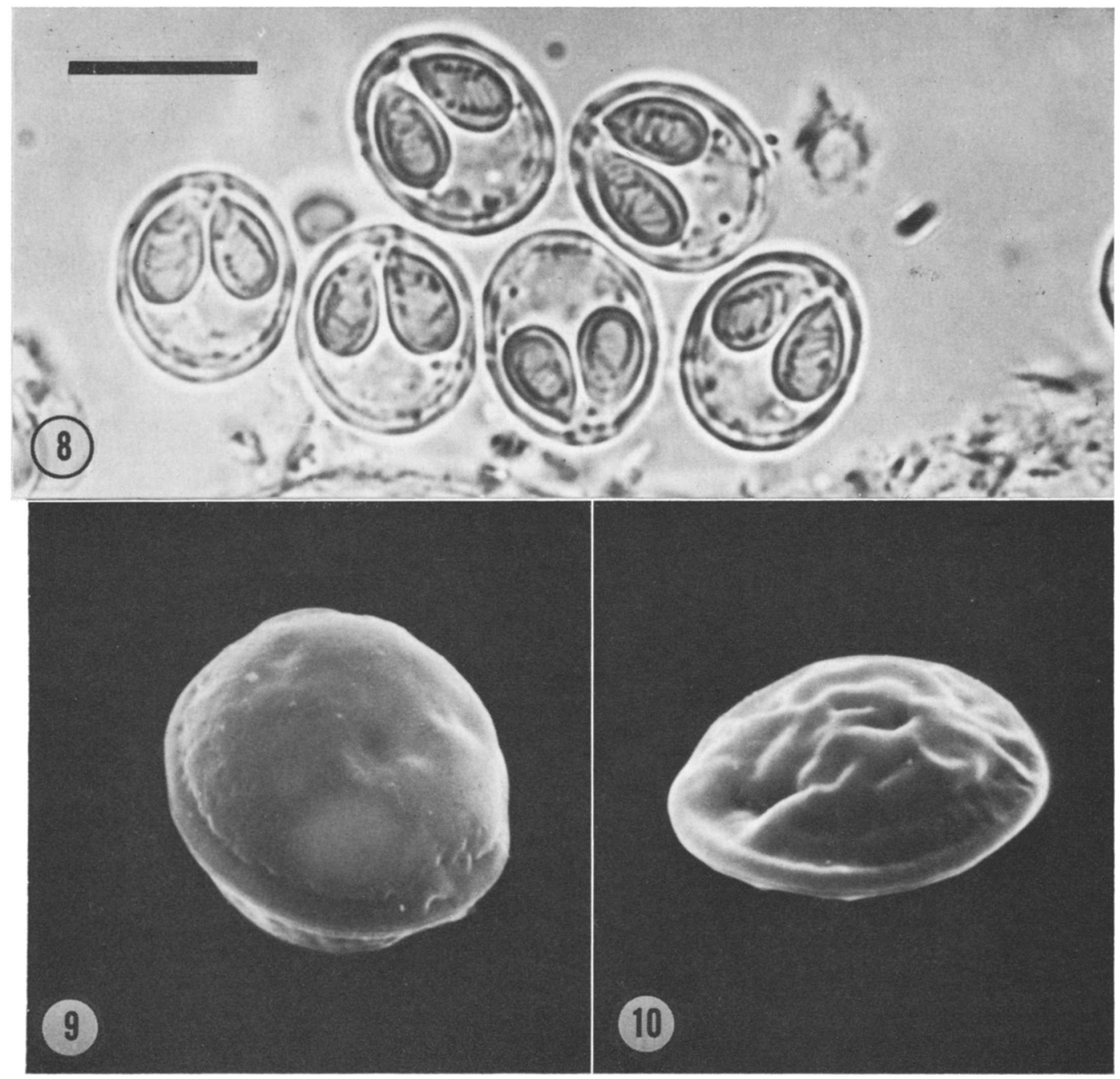

Figure 8. Fresh spores of $M$. cartilaginis from the bluegill. Note uniform appearance of this group of spores selected at random. $\times 2,800$; the line indicates $10 \mu$.

Figures 9, 10. M. cartilaginis spores seen in scanning electron microscope. 9. With smooth shell. 10. With the usual, somewhat shrunken appearance of the shell. In both cases, note absence of furrow along sutural line as well as lack of mucous strands on the surface.

a solid base for species and strain distinctiveness in Myxosoma and Myxobolus.

We would like to avoid giving the impression of mistaking a single developmental stage, the spore, for the whole organism with all its developmental changes and stages. The importance of the spore shape and structure is due to a well-known lack of really distinct characters of the trophozoite, both on the light microscope and on the electron microscope level.

Although the spores of both species here reported were not treated in exactly the same manner, we feel that the differences cited will prove to be valid. The study of $M$. cerebralis spores is not possible without using a concentrating technique. There is no indication that the mucous envelope of $M$. cerebralis is produced during pepsin digestion because we saw it previously on spores not so treated. The mucous envelope has also been observed on other Myxosporidea not treated with pepsin solution (Lom and Vavra, 1963). The spore 
wall of $M$. cerebralis is so tough that it is difficult to believe that pepsin solution would produce the spectacular furrow.

In addition to light microscopy to observe the shape and inner structure of the spore, we used scanning electron microscopy to bring out the surface patterns. Thus far, no data exist on this subject in Myxosporidea, but the ultrafine outer sculpturing and surface patterns revealed by this technique may be of great interest for taxonomy. Sutural markings, ridges, and folds can sometimes be seen on fresh spores of Myxosoma and Myxobolus; it is probable that this was accentuated by our preparation methods, resulting in shrinkage of the spore wall (Figs. 6, 7, 10). In fresh spores, such folds may be made more distinct by vital staining and, in fact, they do not represent artifacts. The smooth-shelled spores (Figs. 5, 9) seem on the other hand always to represent a small part of the sample, and appear sometimes even more swollen than natural; the possibility is not excluded that they are rather immature spores.

\section{LITERATURE CITED}

HNath, J. C. 1970. Whirling disease in the state of Michigan. J. Parasit. 56 (4, Sect. 2): 273.

Hoffman, G. L. 1970. Intercontinental and transcontinental dissemination and transfaunation of fish parasites with emphasis on whirling disease (Myxosoma cerebralis). In A Symposium of the American Fisheries Society on Diseases of Fishes and Shellfishes, Spec. Pub. No. 5, 526 p.

C. E. Dunbar, and A. Bradford. 1969. Whirling disease of trouts caused by Myxosoma cerebralis in the United States. Spec. Sci. Rep.-Fish. No. 427, U. S. Fish and Wildlife Service, $15 \mathrm{p}$.
R. E. Putz, AND C. E. Dunbar. 1965. Studies on Myxosoma cartilaginis n. sp. (Protozoa: Myxosporidea) of centrarchid fish and a synopsis of the Myxosoma of North American freshwater fishes. J. Prot. 12: 319-332.

Kudo, R. 1920. Studies on Myxosporidia. III. Biol. Monographs 5, 265 p.

1921. On the effect of some fixatives upon myxosporidian spores. Tr. Am. Micr. Soc. 40: 161-167.

Lom, J. 1964. Notes on the extrusion and some other features of myxosporidian spores. Acta Protozool. 2: 321-327.

- 1969. On a new taxonomic character in Myxosporidia, as demonstrated in description of two new species of Myxobolus. Folia Parasit. (Praha) 16: 97-103.

_, AND J. VAvra. 1963. Mucous envelopes of spores of the subphylum Cnidospora (Doflein, 1901). Vestn. Cs. Zool. Spol. 27 : 4-6.

MarszaleK, D. S., AND E. B. SMall. 1969. Preparation of soft biological specimens for scanning electron microscopy. Scanning Electron Microscopy 1969 Proceedings 2nd An. Scanning Electron Microscope Symposium, IIT Res. Inst., Chicago, Ill., USA.

Plemn, Marianna. 1904. Über die Drehkrankheit der Salmoniden (Lentospora cerebralis/ Hofer/Plehn). Arch. f. Protistenk. 5: 145166.

Ramirez Medina, A. 1962. Generalidades sobre mixosporidios y enfermedades que desarrollan en los peces de aqua dulce. Bol. Zootecn. Cordoba 18: 1269-1277.

Shulman, S. S. 1966. Myxosporidii fauny SSSR. "Nauka" Publishing House, Moscow-Leningrad, $506 \mathrm{p}$.

WALliker, D. 1968. The nature of the iodinophilous vacuole of myxosporidan spores, and a proposal to synonymize the genus Myxosoma Thelohan, 1892 with the genus Myxobolus Bütschli, 1882. J. Prot. 15: 571-575.

YASUTAKE, W. T. 1970. Myxosoma cerebralis infection of trout in the western United States. J. Parasit. 56 (4, Sect. 2): 691. 